Filología y Lingüística 46 (1): 321-324

Abril - Setiembre 2020

ISSN: 0377-628X / EISSN: 2215-2628

Doi: https://doi.org/10.15517/rfl.v46i1.41230

URL: https://revistas.ucr.ac.cr/index.php/filyling

\title{
Jörg Dünne y Hanno Ehrlinger (Eds.). Ficciones entre mundos: Nuevas lecturas de "Los trabajos de Persiles y Sigismunda [sic]" de Miguel de Cervantes. Kassel: Reichenberger, 2017, 306 páginas
}

La "Introdución" (1-16) plantea, de entrada, la pluralidad de mundos que Miguel de Cervantes desarrolla en Los trabajos de Persiles y Sigismunda (1617). Llama la atención que, a partir de la etimología de "vagabundo/vagamundo" (2), calificativo que el narrador utiliza para personajes secundarios o que se les adjudica también a los protagónicos por parte de otros personajes, los dos editores planteen su condición de exiliados, fugitivos y viajeros, dentro de un mundo convulso y peligroso, como puede darse cuando se producen aventuras marítimas y se viaja hacia tierras incógnitas y lejanas. Esta capacidad de expandirse / trasladarse marca la novela de Cervantes, para que los editores y los participantes de este volumen se interroguen sobre el modelo de la novela de aventuras, las posibilidades de alusión a los problemas socioculturales y políticos de la España del siglo XVI, así como a los principios de la probabilidad y de la salvación, que permiten encontrar la pertinencia no solo del peregrinaje, sino también de los obstáculos a los que se enfrentan los protagonistas. Así, los editores dan en el clavo para justificar el título del libro: vagar por el mundo permite concebir otros mundos (5), alternos y diferentes, que pueden trastocar hasta el orden de la religión o de la política (7) y permiten observar la pluralidad de mundos tanto en sentido geográfico como metafórico).

La primera sección del libro, "De Heliodoro a Cervantes" (17-43), reúne tres artículos. En "Heliodoro en Cervantes: artificios griegos y parejas divinas entre dos mundos" (19-43), Mercedes Blanco parte del concepto de imitatio, de grandes resonancias hasta el Romanticismo, para plantear como un "autor imitado es entonces ese yo ideal, ese otro especular, en quien el escritor pretende mirarse y a quien tal vez sueña con suplantar" (22), de una imitación voluntaria, declarada y programática. Su débito está en lo que se llama el "artificio griego" (24) con ese manejo de la información y la trama in media res; su finalidad es comunicar una tensión emocional que crea expectativas narrativas (hacia atrás y hacia delante) en materia de la información (diferir, seleccionar, confesar la ignorancia), que Blanco, con una gran pertinencia, coteja cuando Periandro cuenta su relato de aventuras corsarias y ella lo complementa en el par Cariclea / Sigismunda en tanto sistema análogo en la presentación / construcción de personajes (37). Por su parte, en "Sufrir, dudar, vacilar: Campos de tensión en la narrativa de Heliodoro y Cervantes" (45-64), Andrea Stahl ofrece, a partir de estos tres verbos, cómo funciona la persuasión de la "acción y de afectos" (45) a la hora de plantear las decisiones / vacilaciones de los personajes; indica que "pone en primer plano la posibilidad de concretar y controlar esquemas del yo y del mundo" (46, la cursiva es del texto), porque el par ira (acción) / duda (postergación) desemboca en orientaciones afectivas y gnoseológicas. ¿Estabilidad o perturbación?, ese es el dilema, para que la vacilación sea una concreción del "obrar divino" (51) y el "sufrimiento afectivo de los personajes y el desorden que este genera" (55) tengan en Cervantes una forma de resiliencia ante la ira y los avatares del destino. Esto implica que las interrupciones y los fracasos no son entendidos como sucesos neutros y la tensión (para los personajes y para el lector) surge 
en este desequilibro / distancia entre el deseo y el éxito de la acción. Por último, Christine Marguet ubica al texto cervantino dentro de una tradición narrativa en "El lugar del Persiles en la novela barroca española" (65-86); se trata de la novela de aventuras y sus estrategias en materia de construcción del relato en esa polarización "entre ficcionalidad declarada y fingimiento particular" (68), que para Marguet tienen en el Persiles y en Guzmán de Alfarache, respectivamente, sus modelos. La escasa publicación de novelas helenizantes posterior a 1620 frente a las que reivindican la forma de memorias o sermones, le permite a Marguet plantear la preeminencia de la confesión / desengaño en la novela de aventuras "que hace incuestionable la credibilidad de lo contado" (73), frente a la autorreflexividad ficcional del Persiles (72). Ella proporciona tres ejemplos: El soldado Píndaro (1626), de Gonzalo de Céspedes y Meneses, Soledades de la vida y desengaño del mundo (1657), de Cristóbal Lozano, y Escarmientos de Jacinto (1645), de Jacinto Funes de Villapando.

La segunda sección del libro, "Lecturas del Persiles" (87-234) reúne ocho trabajos y constituye su parte más voluminosa. En "De Barataria a los mares septentrionales: análisis y comparación de los episodios insulares del Quijote y del Persiles" (89-110), Ingrid Simson se propone un ejercicio de comparación intratextual retomando el motivo de la "ínsula" en Cervantes. Si la "isla" ha servido como pretexto y "proyección para fantasías y deseos" (8990) dentro de su percepción eurocéntrica, su ligamen con la periferia y lo estático establece un sistema de oposiciones entre lo cerrado y lo abierto, para que los libros de viajes, la cartografía y la geografía de los siglos XVI y XVII desarrollen su impronta. Simson explica apenas el episodio de la Ínsula Barataria, cuyo tópico es el buen gobierno, dentro de ese fingimiento de "isla imaginada" (91), mientras se interesa por ese escenario de "islas frías y hostiles" (99) en el límite extremo de Europa, habitadas por bárbaros infieles. Jörg Dünne retoma el interés por las novelas de aventuras, cuya estructura de base es la repetición en 'Las aventuras del 'lugar' en el Persiles" (111-128). La configuración estereotipada de los personajes resulta evidente allí en donde los espacios, en el sentido moderno del término, son cambiantes. Por eso, él utiliza mejor la definición de "lugar", más acorde con Aristóteles en tanto "recipiente de un cuerpo" (114), para trazar sus consecuencias en el Persiles, en esa mezcla no solo de cosmografía y retórica, sino también de afectividad moral a causa de la cual un cuerpo se traslada: del "lugar topológico" pasamos al "lugar tópico" (116), para que los espacios insulares sean el centro de atención de un movimiento aleatorio (117). El texto cervantino nos enfrenta, entonces, al "horror vacui", al proponerse esa falsa etimología que hace de "locus" el origen de "locura", siguiendo a Covarrubias (119). Se trata de uno de los artículos más sugestivos del volumen.

Por su parte, en "Hombres lobo. Soberanía y destierro en el Persiles" (129-148), Stephan Leopold desarrolla un largo excurso para plantear dentro del eje de la combinación / selección de Roman Jakobson, ese entrecruzamiento que se despliega en el engarce entre la historia encubierta de los protagonistas y la de los relatos menores. Toma como ejemplo a Antonio, Clodio y Rutilio y sus naufragios en los Mares del Norte, en tierras de destierro en donde abundan los lobos o el mismo peligro se disfraza en piel de lobos; Leopold habla de una "amenaza lobuzna" (135), mientras su simbolismo medieval se asocia con la condena o proscripción que el monarca sancionaba para situarlo "fuera de la ley" (137). Retoma luego la historia de Auristela y su descenso en una Roma plagada de peligros y obstáculos, pero no establece esa relación que nos propone con las historias menores, al menos en este aspecto del simbolismo del "hombre lobo". De gran coherencia y un desarrollo consistente es el artículo de Walter Marx con el título de "La estructura del Persiles, la tipología cristiana y el espacio simbólico" (149-169), quien parte 
de la hipótesis de una estructura teleológica en Cervantes, pues "secularizó ese modelo salvífico o histórico-filosófico" (149), para que las repeticiones y su dispositio amplifiquen y redupliquen en una forma simétrica o especular, al entrelazar motivos (151) y narraciones, lo cual se explica profusamente en el apéndice comparativo. Pertinente en este sentido, es su afirmación de que las peripecias de los personajes secundarios en los tres primeros libros prefiguran el accionar de la pareja Auristela / Periandro en Roma, dentro de un movimiento hacia la luz, cuando se visten de peregrinos (153) o se concibe ese movimiento gravitacional / cosmológico, del norte, tenebroso y oscuro y alejado de Dios, hacia el sur, católico, civilizado y de claridad (156). Enlaza con el anterior el breve artículo de Xuan Jing, "El juego divino. Dios como estratega en el Persiles" (173-182), que retoma la relación que Marx ya había comentado en la historia de Jacob, usurpador de la gracia y de la legitimidad dinástica; Jing la lleva al terreno de una "moralidad dudosa [...] con artimaña y disimulo" (172), con el fin de problematizar tanto la legitimidad como sus estrategias dentro de la teoría del juego de Steve Brams. Este afirma que la divinidad es un jugador que prefiere un contrincante con libre albedrío y digno (173), mientras crea estrategias al manipular las decisiones del ser humano. Se ejemplifica cuando la divinidad desea imponer su voluntad contra el orden establecido de la primogenitura de Esaú, o cuando, en el caso del Persiles, se justifique la renovación de las costumbres bárbaras como el canibalismo o la consumación de la noche de bodas. Extraño de menos un cotejo o un apoyo textual a esta lectura tan interesante, lo cual veo también en algunos de los artículos de esta sección, muy especulativos en sus atractivas interpretaciones, pero con poco desarrollo textual.

Lo mismo vale para aquellos artículos en donde el Persiles se considera un simple excurso, sin que se explique en forma pertinente cómo un elemento o una determinada temática encuentran su sentido en la generalidad de la novela, a menos de que sea un análisis exhaustivo de un capítulo, episodio, o de una temática específica que atraviese el texto. Por ejemplo, Blanca Santos de la Morena quiere replantear, en "Sobre suicidio y duelo: El Concilio de Trento y el tema de la muerte en el Persiles" (183-200), un tratamiento de la muerte a partir de dos actos que implican arriesgar voluntariamente la vida y ponerse fuera de la voluntad de la divinidad. La relación del Persiles con el Concilio de Trento y la propaganda contrarreformista es una constante de la crítica cervantina y, en la práctica cotidiana, regulariza el duelo y el suicidio como atentado a los designios divinos; habría que ver sus consecuencias en la teología de "salvación cristiana" y la censura de un comportamiento errático que conduce a la muerte (asunto que sería necesario analizar en relación con el Concilio), cuando las decisiones humanas se cristianizan en esa "desesperación ante los trabajos y adversidades que se presenta en el camino vital" (193). En "Fidellidad e idea novelesca. La ética del amor en el Persiles" (201-221), Gernot Kamecke constata la significación del "casamiento místico entre Cristo y la Iglesia romana" (201) y su transvase en el par Persiles / Sigismunda, pero el amor en tanto finalidad y esencia de los "trabajos" conduce en esta novela a cuestiones que Cervantes pone en la práctica (203) y que -yo añadiría a Kamecke parafraseando a Inmanuel Kant- no son del orden del "amor puro" sino de la "razón práctica del amor en general". La concepción del amor neoplatónico no debe verse en abstracto con arreglo a tal teoría o sistema de pensamiento sino en una práctica que la valida: la superación de los obstáculos, las pruebas y la contigüidad / yuxtaposición de los (contra) ejemplos proporcionadas por las historias secundarias (207) comprueban "una casuística ética" (208) que va exponiendo las condiciones subjetivas y colectivas de un verdadero / falso amor y Kamecke comenta las historias intercaladas en su valor demostrativo y de apoyatura persuasivamoral de casos específicos. En el último artículo de esta sección, "La música en el Persiles" 
(223-234), Susana Sarfson y Rodrigo Madrid apenas esbozan algunos elementos musicales en la novela, entre los que destacan el espacio polifónico de tejidos sonoros reconocibles como pueden ser la diversidad lingüística, mientras que el canto y la música se ponen en ejecución dentro de esa concepción que las aúna a la Poesía y a los afectos de la pasión amorosa.

La última sección del libro, "El Persiles y otros textos del Siglo de oro" (235-295) recoge tres trabajos cuya base es la comparación sincrónica. En "Opacidad táctica y alteridad en los Comentarios Reales del Inca Garcilaso y en el Persiles", Fernando Nina se acoge al concepto de "opacidad táctica" que expone la crítica chilena Ana Pizarro en materia de autoridad y del manejo discursivos, para configurar una estrategia difusa y al margen del centro y de la historia. Pues bien, Nina se apoya en ella para visibilizar las contaminaciones y el contacto (243) en la intentio autoris del Inca Garcilaso. Aquello que los cronistas españoles han desdeñado y no han abordado del mundo quechua por su desconocimiento de esta lengua y cultura, Cervantes lo llevaría al terreno de lo bárbaro / civilizado, con consecuencias en el origen de las múltiples narraciones y el contrapunteo de una realidad polimorfa frente a "una identidad única e impermeable" (248) del espacio europeo. Es un artículo denso y de una lectura difícil teóricamente hablando en sus primeras páginas. Por su parte, José Luis Losada Palenzuela en "Desplazamientos de la imagen septentrional: Polonia en La historia de las fortunas de Semprilis y Genorodano" (252-273) analiza esta novela de Juan Enríquez de Zúñiga, publicada en 1629, desde la perspectiva de la "alteridad", aunque la polarización norte / sur tal y como la concibe el Persiles no se puede aplicar aquí en su dimensión que configura un exotismo (254), toda vez que el personaje del rey Kasimiro es discreto y bondadoso (257) y el reino de Polonia se sitúan en un impreciso este de Europa, en un intento por "superar conceptualmente las connotaciones sociopolíticas negativas" (261) de una imaginatio borealis (extraño, exótico, bárbaro). Por último, Hanno Ehrlicher no hace tanto un recuento de la impronta de Heliodoro en un género específico, sino que la aplica a textos de Montalbán, Calderón de la Barca y Rojas Zorrilla en "Dramatizaciones de la novela de corte heliodoriano en el teatro áureo" (275-295). Ehrlicher se centra en el manejo de la intriga dramática y la propuesta de conocimiento maravilloso que implica contradecir la experiencia empírica sobre el color de la piel de Cariclea frente al lienzo pintado de la diosa que la madre miró en el periodo de su gestación; explicación que él denomina como el "efecto Andrómeda" (278) en cuanto manejo del tratamiento de la negritud (lo extraño y diferente) en estas piezas dramáticas. No solo confirma "el poder de la imaginación en el proceso de la concepción, a pesar de las críticas provenientes de médicos" (279), sino que también justifica el "prodigio" o la "maravilla" en tanto naturalización de lo extraño y al servicio de la "máquina" barroca de efectos, tal y como se presentan en la versión libre de Francisco Rojas Zorrilla del texto cervantino (283). Diferente estrategia dramática encuentra Ehrlicher en Los hijos de la Fortuna, de Juan Pérez Montalbán, en donde no se presta atención a este "extraño" origen del color de la piel porque interesa centrarse en la peripecia definitiva (290), o en la pieza de Calderón de Barca con el mismo título, en donde desde el principio se introduce el origen del color de piel dentro de una filiación problemática, resuelta no pseudocientíficamente como en Pérez de Montalbán sino dentro de una filiación conflictiva (292).

Jorge Chen Sham

Academia Nicaragüense de la Lengua Academia Norteamericana de la Lengua Española Universidad de Costa Rica San José, Costa Rica 